\title{
The Practice Unification of Disciplinary Construction and Talent Cultivation Against the Background of "Double First-class" Strategy in Chinese Higher Institutions
}

\author{
Jinzhu Zhang \\ School of Humanities \\ Tianjin Polytechnic University \\ Tianjin, China
}

\author{
Hongquan Lin \\ Personnel Division \\ Tianjin Polytechnic University \\ Tianjin, China
}

\begin{abstract}
Talent cultivation is an important function of modern universities and one of the essentials of constructing first-class disciplines. Disciplinary construction and talent cultivation are two mutually supported missions which run through the governance of universities all the time. The evolution of new knowledge production model and the emergence of the wave of internationalization of higher education in the world further regulate the practice of discipline construction and talent cultivation. Meanwhile, the integration and innovation of knowledge and the cultivation of talents has become the dual kernel of discipline construction. Adhering to the concept of value rational education, realizing the conscious compliance of administrative power and academic power, insisting on the unification of discipline construction and talent cultivation in educational practice is the essence of the construction of "Double First-class" in universities. It is also the logical starting point of university governance. Discipline construction and talent cultivation have the same core accomplishment, which are two different aspects of the same university governance process in the field of university, and the main practice path is the unification of teaching and learning and scientific research.
\end{abstract}

Keywords-"Double First-class" Strategy; higher institutions in China; disciplinary construction; talent cultivation; practice unification

\section{INTRODUCTION}

In the practical administration of Chinese universities, disciplinary construction and talent cultivation have not realized the unification in real sense, and it has become the paradox of higher education to pay attention to the cultivation of talents, which is known as "lip service" but not "real" higher education, which has seriously affected china's "Double First-class" construction strategy to achieve its comprehensive goals. Is the antagonism between disciplinary construction and talent cultivation really an unsolved educational proposition? If not, what is the theoretical basis and practical path of the unification of the two elements?

\section{THEORETICAL BACKGROUND}

\section{A. The Evolution of Knowledge Production Modes}

Since the birth of the University of Bologna, Italy, the existence and development of the university has been closely related to knowledge production. From the middle ages to the 19th century, the university was the place where the students pursued the universal truth. Knowledge itself was the legal basis of the existence of the university, and imparting knowledge was also the main purpose of the university activity (Newman 1996). From the end of the 19th century to the 1960s, knowledge production became a major activity in addition to university teaching. Universities gradually take the dual identity of knowledge transmission, the maintainer and main producer of knowledge. Universities constantly realized the roles of knowledge reproduction and knowledge innovation through the construction of different disciplines and the cultivation of talents for the society. Today, with the rapid development of global economic integration and the rising tide of popularization and internationalization of higher education, the mode of knowledge production is changing with the fundamental change of the nature of knowledge. At present, scholars generally divide the production mode of knowledge into three types: one is the traditional knowledge production model based on Newton model; the other is the traditional knowledge production mode, which is mainly based on single-discipline research, is supposed to use the method of cross-disciplinary research in the application environment and places more emphasis on performance and social role in the process of knowledge production(Kerr 1963); the third model of knowledge production takes "cluster group", "network network" and "ecosystem ecosystem" as the core elements and concepts(Zhang 2013; Wu 2014). Among them, the 2nd model of knowledge production has obtained the relatively consistent approval. The theory of knowledge production adopted by OECD in its 1998 book the Transformation of academic Research in Transition by Gibbons is also the theory of model 2 of knowledge 
production. There is a huge difference on knowledge production mode between the two models in terms of the time, space and organization. In the second model of knowledge production, the monopoly and exclusive position of university in knowledge production and innovation is completely overturned, and the scientific research paradigm of "ivory tower" of university also disintegrates. As a response to the transformation of knowledge production mode, the construction of university disciplines has produced new rules and regulations, which makes the discipline construction in modern university governance more and more inseparable from the combination and unification with talent cultivation. In other words, in the long run, the construction of the first-class discipline in the future must be based on the cultivation of knowledge and talents.

\section{B. Characters of Knowledge Production}

According to the research of six scholars such as Michael Gibbons, the 2nd model of knowledge production has four characteristics: first, situationality, that is, knowledge production will be more placed in specific situations. The process of knowledge production, characterized by pure speculation, is no longer the only way to produce knowledge. Knowledge production mode based on practical application situation will appear more frequently. The specific situation of knowledge application will also play a more and more important role in knowledge production. The second is interdisciplinary, that is, knowledge is generated mostly from the interactive application of multidisciplinary in specific situations. The third is multi-sources and heterogeneity. In the second generation of knowledge production model, knowledge is created by various organizations and institutions, and there are various characteristics among knowledge in different fields. The fourth is relevance. The production of knowledge is not only due to the pure pursuit of truth, but also to the needs of society. The evaluation of knowledge has also moved from the one-dimensional evaluation of the academic itself to the multidimensional evaluation of society, economy, politics and culture (Gibbons 2010).

The four characteristics of the 2nd model of knowledge production point out the inseparable relationship between knowledge and practice and the interdisciplinary nature of knowledge. In other words, the production of knowledge in the new era can be realized mainly through the active practice of human beings and the relationship between different disciplines established by human practice.

\section{Implications to Chinese Higher Education}

According to the 2nd model of knowledge production theory, the discipline knowledge is mainly derived from the application of human knowledge in the specific situation, and the talent is the origin of the discipline knowledge. That is to say, knowledge is the main building material of disciplinary construction, and talent is the source of knowledge. In this way, the logic chains between theory and practice should be followed in the construction of "Double First-class" universities in China, that is: theoretically, the construction of modern first-rate universities is absolutely inseparable from the construction of first-class disciplines. The construction of first-rate disciplines cannot be separated from the accumulation and innovation of knowledge, and talents are the ultimate sources of knowledge. Practically, first-class disciplines contribute to the cultivation of firstclass talents, and the scientific research of first-class talents promotes the production and innovation of knowledge. Knowledge production and innovation provide an inexhaustible power for the sustainable development of topclass disciplines. Thus, it can be seen that the cultivation of talents and the accumulation and innovation of knowledge are two aspects of the same process of discipline construction, and are the dual core of the construction of first-class disciplines in China. The unification of the two in the process of educational practice is the inevitable rule of the evolution of knowledge production mode to the construction of "Double First-class".

\section{RESEARCH ANALYSIS}

\section{A. The Unification of Talent Cultivation and Disciplinary} Construction as the Logical Starting Point of University Governance Under the Current Educational Ecology in China

According to Hegel's understanding that the logical starting point reveals the most essential stipulation of the object of study, it is the simplest and most abstract category in the discipline, and the foundation upon which the discipline is founded. The whole development of the theoretical system of the all disciplines is contained in this germ $(\mathrm{Qu}$ 1998). Promoting the construction of the first-class university through the construction of the first-class discipline and realizing the functions of the university in an all-round way are the great governance logic of the universities based on the construction of "Double First-class" at present in China. The unification of talent cultivation and disciplinary construction is the logical starting point that runs through the logical structure of university governance in our country, that is, talent cultivation and disciplinary construction are educational activities that run through the university governance all the time. The unification of practice is the key factor to decide the realization of university functions.

\section{B. Importance of Talent Cultivation at Universities}

Talent cultivation and scientific research have always been the basic activities of the university and the legitimacy of the existence of the university. Although some scholars believe that the primary function of the university is relatively single, the main purpose is to cultivate the talents needed by the society at that time. "From the days of the establishment of medieval universities until the end of the 18 th century, universities were only a place for teaching" $(\mathrm{Qu}$ 1998).

In practice, the pursuit of knowledge was accompanied by the birth of universities. But before the 19th century, the so-called scientific research came more from the individual's "leisure", with a strong individual features. "According to the paradigm of modern science, medieval universities did not 
have scientific research. But the absence of scientific research does not mean that there is no research. For the progress of advanced human knowledge, research is eternal and universal"(Wang 2015).

Presently, talent cultivation, scientific research and social service are regarded as the three main functions of modern universities. The university governance in China must face not only the more complicated internal governance logic structure, but also the fierce challenges of higher education internationalization from the outside world.

\section{The Changing Realities and Its Impacts on Universities in China}

The process of world economic integration has given birth to the inevitable trend of the international development of universities in the world and accelerated the free flow and reconfiguration of the resources of higher education in the global scope. The development level of universities also directly affects the competition and possession of international higher education resources in China and has an increasingly far-reaching influence on the realization of the strategic goal of "Double First-class" construction. With the combination of the world's leading disciplinary construction and talents, the university governance in the western developed countries has formed a benign cycle of development model of the unification of disciplinary construction and talent cultivation. Compared with the developed countries, there is still a big gap between the disciplinary construction and the level of talent cultivation our universities is at its preliminary stage, which seriously weakens the cohesion of our universities to the resources of higher education. The statistics report of Ministry of Education shows that the total number of Chinese students studying abroad has reached 413900 in 2013, and the number of undergraduate students has increased rapidly to 93768(MOE 2014). The massive loss of higher education resources is a great obstacle to the disciplinary construction and talent cultivation in our country, which is very unfavorable to the realization of the "Double First-class" strategic goal at present in our country.

In view of the complex internal and external educational ecological environment, the university governance of our country cannot realize the unification of the two in the educational practice if the relationship between talent cultivation and disciplinary construction is not properly handled, and will not guarantee the smooth realization of the university functions. This is because; first-class universities should have corresponding first-class university functions. The first-class university can only bring about the quality enhancement of scientific research and talent cultivation through the first-class disciplinary construction. Only highlevel talents can make high-level scientific research and produce high-level scientific research results. High-level scientific research results can support the sustainable development of first-class disciplines and thus serving Chinese society better. The formation of the logical relationship chain of this series of causal cycles all depends on the unification of talent cultivation and disciplinary construction. If there is no disciplinary construction, how can we cultivate talents? What's the point of scientific research without talents? Is it an empty talk to serve the society without the unification of talent cultivation and disciplinary construction? It is obvious that talent cultivation and disciplinary construction are two educational propositions which are necessary and sufficient in the development of "Double First-class" strategy of universities in China. Since the unification of the two is so important, why do we form the educational paradox of attaching importance to disciplinary construction and neglecting the cultivation of talents in our educational practice? What is the path to the unification of the two?

\section{UNIFICATION BASED ON THE RATIONALISM AND POWER THEORY}

\section{A. Criticism on the Division of Disciplinary Construction and Talent Cultivation Based on the Rationalism and Power Theory}

The disciplinary construction and the talent cultivation practice are the main contents of the university governance. The value pursuit and rational view in two aspects are directly related to the value reasoning and the instrumental rationality, which has affected the unification of disciplinary construction and talent cultivation in educational practice.

1) Educational rationalism and its implications: From the view of educational Rationalism, the concept of higher education should give more consideration to the long-term significance of education to the development of the state and society. In terms of university governance in China, regardless of disciplinary construction or talent cultivation, the ultimate aim is to apply the accumulated and innovative knowledge and civilization to the direct service of human beings through educational activities. These activities are supposed to develop students' potentials, and finally to cultivate high quality citizens for the society, and promote the continuous progress of the society. Under the guidance of such values, talent cultivation and knowledge production becomes the dual core of the disciplinary construction, and the practice unification of the two has become a natural process that scrupulously adheres to the University rationality.

However, the reality of most universities in our country is like this: the decline of value rationality and the spread of instrumental rationality in the field of higher education, the purely instrumental concept of education have caused the short-sighted behavior of the disciplinary construction. in order to improve the disciplinary rankings in the short term and increase the educational funds from the state, some universities use various methods and schemes at the expense of the long-term development interests of the university. This kind of acts will definitely lead to the separation of the disciplinary construction and the practice of talent cultivation, not to mention the university mission. Today, if we do not rationally examine the national responsibility and national interests on our shoulders, "Tsien Hsueshen's question" will surely become the sword of the Chinese university forever. 
2) View of power and its implications on university governance: In addition to the Rationalism, the operation of the university power system also seriously affects the unification of the practice of the disciplinary construction and talent cultivation. Power is the core concept of political science. The first classic definition of power by Dahl (Robert Dahl) is: A has power, which means that A has the power to request B to do what B may not do to his/her will. (Robert 1957). This view of power clearly explains the use of power.

Based on the conception above, scholars like Peter Bachrach, Balazs and Steven Lukes put forward the "two dimensional view of power" and "three dimensional view of power" one after another. The concept of power and the connotation of power gradually expands to reveal the recessive power behavior in the mechanism of power operation. Bachrach believes that power can be damaged or benefited by the recessive power such as "agenda control" and "mobilizing prejudice" to make the interests of the objects damaged or benefited. Steven Lukes divides power into three dimensions: the power to be used clearly, the power to rely on the invisible force and the power to use the self-conscious power. At the same time, the effect of the exercise of power will become more obvious with the increase in the exercise dimension of power. Lukes once judged the effects of forming a conscious power exercise: "It's the highest state of exercising power that the subjects of power require the objects of power to form the thought that conform to the will of the subject of power." That is, it is by controlling the thought and desire of the objects of power to achieve the obedience of the objects of power to the subjects of power? (Lukes 2004)

From Lukes' three dimensional power theory, the power relationship that promotes university governance has formed a strict power system between the government and the university system outside and inside. The government represents the state's will to use the power to carry out the higher education policy that holds the rational education view. Colleges and universities at all levels have the power to choose the power and use the power to implement the policy according to their own rational concepts. The effect of policy implementation will naturally produce different effects because of the different dimensions of power.

Under the guidance of the concept of instrumental rational education, the university will naturally choose the power of self-obedience in the fields of disciplinary construction. In terms of dimensions, the effect of the power exercise that is clearly used in the talent cultivation and disciplinary construction is very different. The effectiveness of the talents training is far less than the effect of the disciplinary construction, and the gap between the two will gradually expand with the passage of time, and it is difficult to achieve the integration and unification of the educational practice.

Lukes' view of "three dimensional power" explains the static dividing reality of disciplinary construction and talent cultivation, and the power theory of French political scientist Foucault makes us see more clearly the power application mechanism in talent cultivation and disciplinary construction of universities.

According to Foucault's understanding, power is "something of a kind of circulatory flow; something that acts only in a chain form; power is used and implemented through a reticule organization, and the individual is always in the position to withstand the power and use the power at the same time, the individual is the carrier of power" (Foucault 1997). "Power expansion is a way of acting on some other behavior; power must pay the price to be implemented" (Foucault 2010). The governance power of the university is scattered and passed to colleges and universities. Universities and the Departments of universities determine their ways of power use and transmission in its own position from their "benefits". It is the difference between the different judgments of this "interest" and the difference of power based on judgments, which eventually leads to the different effects of the power use (the behavior of university governance) in the disciplinary construction and talent cultivation.

\section{B. Unification Under the Guidance of Educational Thought Based on Nationalism}

The aim to reclaim the educational view of value rationality is to reverse the present neglect of talent cultivation at universities so that talent cultivation becomes the real self-conscious power in the behavior of university governance. However, the emphasis on disciplinary construction and talent cultivation does not necessarily mean the integration of both in educational practice. The integration of two also requires all-round transformation and exploration of the concepts in university governance.

1) Unification of disciplinary construction and talent cultivation under the ideology of Nationalism: "The essence of nationalist education thought is to cultivate the deep attachment to the nation, to defend the national security and protect the national interests" (Fan, Huang 2016), which is the legal basis and premise of the unification of the integration of disciplinary construction and talent cultivation. China's nationalist education thought began in the late Qing Dynasty and the beginning of the Republic of China, and has played a special role in the movement to recover the Right of Education (Yang 2008). Although the ideology of nationalism has not become the mainstream of the ideological circle in the subsequent development, the internationalization of higher education in the world has gradually become a trend. The educational ideology of nationalism still shines in China's university education. "In any society or era, this educational ideal, which has extensive influence and dominant position, is the source of the values of mainstream education. It is the spiritual force that drives and guides countless educators to carry out educational practice, and is the educational policy which should be adhered to forever. It is the fundamental standard of justification of practice, legitimacy and purpose; it is also the greatest and most profound educational ideal that has 
influenced the educational policies and practices in different periods of China over a hundred years; in twenty-first century, the ideal of nationalist education still has its legitimacy and guiding significance to education reform and development. Meanwhile education should also be adapted to the challenges of the era of globalization, the integration of cosmopolitanism responsibility"(Shi 2011). The disciplinary construction should serve not only for knowledge innovation but also for the national development. The disciplinary development itself is not sufficient to embody the nationalist educational thought. Talents, as the main theme of construction, are the realistic carriers of the Chinese ideology of education.

On the one hand, the development of disciplines is mainly reflected as the main explicit forms by knowledge innovation. On the other hand, the disciplinary construction is not only about the accumulation of knowledge and the introduction of academic talents, but also an important aspect of the disciplinary construction. The disciplinary culture of Chinese university should not only bear the deep temperament of Chinese culture, but also broadly introduce the Chinese cultural tradition, and cannot be replaced for the development and integration of the world culture. The contribution of disciplines is to absorb the brilliant essence of the world culture. The formation of the disciplinary culture is realized mainly through the cultivation of talents. The cultural characteristics and spirit of the discipline are given by the builders and the talents of the discipline. The fragmentation of disciplinary construction will inevitably cause damage to disciplinary culture, and ultimately lead to the loss of nationalism education thought in disciplinary construction.

Although nationalist educational ideas still have academic discussions of nationalism and internationalism, individualism, populism, and humanism, the pursuit of national interests is the motive force of educational reform, and every reform of education is to pursue the maximization of national interests or the pursuit of new national interests"(Shi 2007). Any academic debate cannot shake the mainstream direction of China's "Double First-class" construction of nationalism. In practice, we must adhere to the concept of values Rationalism, take the future of the nation in mind, create knowledge and cultivate talents for the great rejuvenation of the Chinese nation.

2) Essence of the unification: The combination of disciplinary construction and talent cultivation is the unification of university teaching and scientific research based on common accomplishment. The disciplinary construction mainly involves the accumulation and innovation of knowledge. talent cultivation mainly involves the inheritance of knowledge related to teaching. The two aspects are closely related to knowledge and are similar in structure and connotation. The combination of disciplinary construction and talent cultivation in educational practice is essentially the unification of teaching and scientific research.

The disintegration of teaching and scientific research in universities has been criticized by higher education researchers and is taken as another educational paradox in higher education. Many educational administrators and teachers mistakenly believe that teaching is only about the inheritance of existing knowledge, research is the innovation and creation of knowledge, and they are essentially two different points. Even the Cardinal Newman also believes: "Discovery and teaching are two distinctive functions, and they are also very different gifts. At the same time, it is not common to have both of these two abilities. And it is impossible to have leisure and energy to acquire new knowledge (Newman 1996).

\section{CONCLUSION}

The relationship between teaching and scientific research is not an isolated one, but it is a key ecological element of cooperation and symbiosis in higher education ecology. Scientific research is the material basis for the existence of teaching. The main product of the scientific research is the knowledge of innovation, which has lost the reproduction of knowledge. In scientific research, the content of teaching will be exhausted and the teaching will lose the material basis for continuous development. At the same time, the process of scientific research itself is also a higher level of teaching process. This is because the essence and ultimate aim of teaching is to cultivate talents through the inheritance of knowledge. Talent is the main body of scientific research and the decisive factor in scientific research. In this sense, the process of teaching should be involved in more scientific research elements. Thus, scientific research is the reason for the existence of teaching. If teaching and scientific research have lost any of them, and the other is bound to die out. The university is called upon to achieve the unification of scientific research and teaching. The balance between the two is lost and the quantity of the university can only be an extremely mediocre university. On the contrary, the unification of scientific research and integration of teaching and scientific research will promote the construction of firstclass discipline and the cultivation of high-quality talents.

\section{ACKNOWLEDGEMENT}

The research in this paper was supported by Tianjin Municipal Education Commission "the 13th 5-Year" Planning Project: Research on the Assessment Standards of Teachers' Professional Developments in Higher Institutions (NO. HE1003)

\section{REFERENCES}

[1] Foucault. The eye of the power. Translated by Yan Feng. Shanghai: Shanghai people's Publishing House.1997.

[2] Foucault. Selected reading of Foucault. Translated by Wang Min an Bei Jing: Beijing University Press.2010.

[3] Fan Shuangli, Huang Fuquan. The Enlightenment of the Educational thought of nationalism to the present Chinese Education. Journal of South China normal University (Social Science Edition),vol.135, pp.58-64, 2016.

[4] Kerr,C. The use of the university. Cambridge, MA: Harvard University Press.1963.

[5] Malcolm Waters. Modern sociological theory. Beijing: Huaxia Publishing House.2000. 
[6] Newman J.H. The idea of the university. New Haven, CT:Yale University Press. 1996.

[7] Qu Baokui, Zheng Jinzhou. Logical starting point of pedagogy: yesterday's View and Today's understanding. Shanghai Education and Scientific Research, vol.34, pp.47-55. 1998.

[8] Robert A. Dahl. The concept of power.behavioral science. Vol.3, pp.201-215, 1957.

[9] Shi Zhongying. Nationalism in Education in the 20th Century: review and discussion. Chinese Journal of Education, vol.38, pp.26-33, 2006.

[10] Shi Zhongying.Responsibility and pursuit of educational philosophy. Hefei: Anhui Education Press, 2007.

[11] Steven Lukes. Power: a radical view. London.Palgrave Macmillan, 2004.

[12] The Ministry of Education. Development report on the international education in China.2014. Retrieved from: http://www.cscse.edu.cn.

[13] Wu Hongfu.(2012). The historical evolution of the relationship between university teaching and scientific research. The Exploration of Higher Education, vol.42, pp.31-36, 2012.

[14] Wang Jianhua. Review of the unification of teaching and scientific research. Journal of Education,vol. 72, pp. 16-25, 2015.

[15] $\mathrm{Wu}$ Xuechao. Theoretical interpretation of knowledge productionconnotation, context, trait and university orientation. Scientific Research, vol. 13, pp.1297-1305, 2014.

[16] Yang Sixin. A historical review of the Nationalist School of Education in the 1920s. Academic research, vol. 47, pp. 110-117, 2008.

[17] Zhang Hongyan. The influence of knowledge production on the talent cultivation mode in Colleges and Universities: a case study of the School of Software and Microelectronics of Peking University. The monthly Journal of Education and academic Science, vol. 83, pp. 58$73,2013$. 